\title{
Third-hand smoke exposure and health hazards in children
}

\author{
G. Ferrante1, M. Simoni2, F. Cibella1, F. Ferrara1, G. Liotta1, \\ V. Malizia1, G. Corsello3, G. Viegi1, S. La Grutta1
}

\begin{abstract}
Third-hand smoke exposure and health hazards in children. G. Ferrante, M. Simoni, F. Cibella, F. Ferrara, G. Liotta, V. Malizia, G. Corsello, G. Viegi, S. La Grutta.

Smoking still represents a huge public health problem. Millions of children suffer the detrimental effects of passive smoking. An increasing number of countries have recently issued laws to regulate smoking in public places. Instead, homes remain a site where children are dangerously exposed to environmental tobacco smoke (ETS). The combination of tobacco smoke pollutants which remain in an indoor environment, the so-called 'third-hand smoke' (THS), represent a new concept in the field of tobacco control. THS consists of pollutants that remain on surfaces and in dust after tobacco has been smoked, are re-emitted into the gas-phase, or react with other compounds in the environ-
\end{abstract}

\begin{abstract}
ment to form secondary pollutants. Indoor surfaces can represent a hidden reservoir of THS constituents that could be re-emitted long after the cessation of active smoking. Human exposure to THS pollutants has not yet been thoroughly studied. Infants and children are more prone to the risks related to THS exposure than adults because they typically spend more time indoors and have age-specific behaviours that may expose them to potential health hazards from THS. Further investigations are warranted to study the health effects of THS relevant to different exposure pathways and profiles. It would also be very important to evaluate how THS may affect the lung development through the in utero exposure during the pre-natal life. We aimed at reviewing recent findings published about THS, with special reference to the effects on children's health. Monaldi Arch Chest Dis 2013; 79: 1, 38-43.
\end{abstract}

Keywords: Environmental tobacco smoke, Children, Lung development, Asthma, Tobacco control, Indoor environment, Third-hand smoke.

1 Consiglio Nazionale delle Ricerche, Istituto di Biomedicina e Immunologia Molecolare, Palermo;

2 Unità di Epidemiologia Polmonare E Ambientale, Consiglio Nazionale delle Ricerche, Istituto di Fisiologia Clinica, Pisa;

3 Dipartimento Universitario Materno Infantile (DUMI), Università di Palermo, Italia.

Correspondence: Giuliana Ferrante, MD, Istituto di Biomedicina e Immunologia Molecolare "Alberto Monroy" del C.N.R, Via U.La Malfa 153, 90146 Palermo (Italy); e-mail: giuliana.ferrante@ibim.cnr.it

\section{Introduction}

Smoking still represents a huge public health problem. Approximately 1.1 billion people are current smokers worldwide and this figure is expected to rise to over 1.6 billion by the year 2025 [1]. Millions of children suffer the detrimental effects of passive smoking. About half of the children in the world live in countries where there is no legislation relevant to tobacco smoking and only $5 \%$ of the world population is protected by antismoking bans [2]. An increasing number of countries have recently issued laws to regulate smoking in public places such as restaurants, bars and workplaces. Instead, homes remain a site where children are dangerously exposed to environmental tobacco smoke (ETS) [3].

Several authors have studied ETS and its effects on children's health. Most of the available papers concentrate on passive smoking as 'second-hand smoking' (SHS), a mixture of the side-stream smoke (emitted from the burning cigarette) and the mainstream smoke exhaled from the lungs of smokers.

Recently, a new type of exposure has been identified. In fact, the combination of tobacco smoke pollutants remaining in an indoor environment has been referred to as the so-called 'thirdhand smoke' (THS), which represents a new concept in the field of tobacco control [4].

We aimed at reviewing recent findings published regarding THS, with special reference to the effects on children's health.

\section{What is Third-hand Smoke?}

THS consists of pollutants that remain on surfaces and in dust after tobacco has been smoked, are re-emitted into the gas-phase, or react with other compounds in the environment to form secondary pollutants.

In particular, while SHS exposure results from the involuntary inhalation of side-stream and main-stream smoke, THS exposure is derived from the involuntary inhalation, ingestion or dermal uptake of pollutants present in air, in dust and on surfaces. THS and SHS are closely related as they co-exist in the first period of THS formation. Later, while SHS is removed through ventilation, THS pollutants may persist in the indoor environments even for several days or months after tobacco have been smoked (table 1). 
Table 1. - Main differences between SHS and THS

SHS

THS

\begin{tabular}{lll}
\hline Exposure route & Inhalation of side-stream and main-stream smoke & Inhalation, ingestion, dermal uptake of pollutants \\
\hline Exposure time profiles & High levels over short intervals & Low levels over long periods \\
\hline Features & Removal through ventilation & Persistence on indoor surfaces and human envelope \\
\hline Repositories & & $\begin{array}{l}\text { Walls, doors, carpets, upholstery, pillows, } \\
\text { curtains, mattresses, clothes, skin, hair }\end{array}$ \\
\hline
\end{tabular}

Hence, the exposure risk to passive smoking does not end when a cigarette has been extinguished and may persist also in the absence of further smoking [5].

\section{Constituents and Transformation of THS}

The main constituents of THS are nicotine, 3ethenylpyridine, phenol, cresols, naphthalene, formaldehyde and tobacco-specific nitrosamines. Physical and chemical transformations of tobacco smoke pollutants take place after their release during smoking. These reactions can occur in a range from few seconds to several weeks or months [5].

Nicotine is the most abundant organic compound emitted during smoking [6]. It has been demonstrated to deposit almost entirely on surfaces persisting for weeks to months, whereas most other tobacco smoke constituents showed more moderate sorptive tendency [5].

Moreover, nicotine can react with oxidant gases normally present in indoor environments (ozone, nitrous acid) to form nitrosamines (TSNAs), such as 1 - ( $N$-methyl- $N$-nitrosamino)-1(3-pyridinyl)-4-butanal (NNA), 4-(methylnitrosamino)-1-(3-pyridinyl)-1-butanone (NNK) and $N$-nitrosonornicotine (NNN). These compounds are classified by the International Agency for Research on Cancer as lung carcinogens [7]. Due to their very low volatility, these carcinogens can per- sist indoors and on the human skin envelope: it is plausible that inhalation and ingestion of TSNAloaded dust as well as dermal contact with contaminated surfaces are the main exposure pathways for such exposure [6].

At last, nicotine can react to form volatile compounds including formaldehyde, that is a known human carcinogen for which there is no safe level of exposure [8].

Thus, indoor surfaces can represent a hidden reservoir of THS constituents that could be re-emitted long after the cessation of active smoking [5].

Since infants are often in close contact with surfaces and dust and they have a higher respiration rate and a lower body weight than adults, even low doses of TSNAs may represent a long-term health hazard [6].

\section{The magnitude of the problem}

The chemistry and physics of tobacco combustion in indoor environments suggest that some THS constituents can remain for long periods after the actual smoking has taken place [5]. Possible repositories of THS are indoor surfaces such as walls, doors, curtains, carpet, upholstery, pillows, mattresses, clothes and even skin and hair [9] (table 2).

Nicotine has also been found to contaminate private homes of non-smokers formerly occupied

Table 2. - Magnitude of THS exposure

\begin{tabular}{lllll}
\hline Author & Duration of exposure & Place of exposure & Outcome & Comment \\
\hline Matt GE, et al [4] & Weeks & $\begin{array}{l}\text { Homes of non-smokers } \\
\text { formerly occupied } \\
\text { by smokers }\end{array}$ & $\begin{array}{l}\text { Significant correlation } \\
\text { with finger nicotine } \\
\text { levels and urine cotinine } \\
\text { levels determined } \\
\text { in occupants }\end{array}$ & $\begin{array}{l}\text { Smoker homes are } \\
\text { dangerous reservoirs } \\
\text { of THS pollutants }\end{array}$ \\
\hline Matt GE, et al [5] & $\begin{array}{l}\text { Previous year } \\
\text { before the study }\end{array}$ & $\begin{array}{l}\text { Automobile cabin } \\
\text { of smokers } \\
\text { and non-smokers }\end{array}$ & $\begin{array}{l}\text { High nicotine levels } \\
\text { on surfaces of smoker } \\
\text { cars }\end{array}$ & $\begin{array}{l}\text { Significantly higher } \\
\text { levels of nicotine } \\
\text { in smoker cars than those } \\
\text { from cars where smoking } \\
\text { bans were imposed }\end{array}$ \\
\hline Schick $\mathrm{s}$, et al $[8]$ & $\begin{array}{l}\text { Previous years } \\
\text { before the study }\end{array}$ & $\begin{array}{l}\text { House of smokers } \\
\text { at the time of the study }\end{array}$ & $\begin{array}{l}\text { Significant correlation } \\
\text { between nicotine } \\
\text { concentration } \\
\text { and the house age }\end{array}$ & $\begin{array}{l}\text { Traditional cleaning } \\
\text { methods cannot remove } \\
\text { the long-standing } \\
\text { pollutants effectively }\end{array}$ \\
\hline
\end{tabular}


by smokers. Even after several weeks, dust and surface nicotine levels are still higher than in nonsmoker homes, with a significant correlation with finger nicotine levels and urine cotinine levels determined in occupants. Therefore, smokers' homes represent dangerous reservoirs of THS pollutants to whom non-smokers are involuntary exposed [4].

Moreover, a recent study found that the smoking status of the occupants during the previous years is a stronger predictor of high nicotine levels in the house than smoking status at the time of the study. The authors also found a significant correlation between nicotine concentration and the age of the house. Similarly, it has been recently observed that the strongest predictor of house dust polycyclic aromatic hydrocarbons (PAHs)is the building age. Therefore, there is evidence that many pollutants accumulate in homes and traditional cleaning methods cannot remove them effectively [8].

The automobile cabin also represents a hazardous environment for non-smoker exposure. Recently, it has been demonstrated that there are high nicotine levels on surfaces of smokers' cars, such as dashboards, upholstery and window glasses. These levels persist days after active smoking took place and are significantly higher than those from cars where smoking bans were imposed or from non-smoker cars [5].

Finally, there is some evidence that THS is detectable on smokerhands with the possibility to spread THS pollutants to other persons or objects [5].

The presence of THS constituents in the air, in dust, and on surfaces of indoor environments accounts for different possible exposure routes. In fact, in addition to exposure to volatile compounds re-emitted from contaminated surfaces through inhalation, there are other potential exposure routes for the less volatile THS components, such as dermal contact and ingestion of dust loaded with THS constituents [9].

Comparing THS with SHS and active smoking, there is evidence that it involves different time profiles of exposure (low level of exposure over long periods $v s$ high levels over short intervals), different kinds of pollutants with different concentrations in different media (air, surfaces and dust) and various kinds of exposure route (inhalation, dermal contact and ingestion). Thus, exposure to THS implies health risks that are not directly, or exclusively, associated with tobacco smoke [5].

All these findings suggest that THS is ubiquitous since it is not limited to the space in which tobacco was smoked and it may represent a serious danger for human health.

\section{Health implications in children}

Human exposure to THS pollutants has not been thoroughly studied to date. Hence, it is not yet possible to fully evaluate what are the health hazards from the exposure to THS. However, it is possible to consider the detrimental effects on human health of some of the known THS compounds. In fact, it is well known that nicotine has a role in carcinogenesis, has adverse effect on vas- cular system and may promote inflammation through oxidative stress, as well as it may alter brain and lung development in children. It is also to point out that nicotine can react with other pollutants to form new compounds, such as TSNAs and formaldehyde, known as potent human carcinogens. Moreover, other tobacco smoke constituents can have detrimental effects on health: PAHs, particularly benzo $[a]$ pyrene, are carcinogenic; oxidant gases can promote oxidant damage and inflammation through the production of free radical species and can trigger allergic symptoms and asthma [5]. At last, a correlation between low levels of tobacco smoke markers and cognitive deficits in children has been shown, suggesting that some compounds in tobacco smoke may be neurotoxic, even at extremely low levels [3].

Undoubtedly, infants and children are more prone to the THS exposure-related risks than adults. In fact, they typically spend more time indoors and have age-specific behaviours, ie. crawling and ingesting non-food items, that may expose them to potential health hazards from THS (table 3). Moreover, children are more sensitive than adults to pollutants in house dust for several factors: increased respiration relative to body size (that determines a higher dust ingestion rate than adults); physiologic immaturity of respiratory and immunologic systems; low metabolic capacity; longer life expectancy [4].

The mechanisms underlying pre-natal and post-natal lung effects of passive smoking exposure are likely to be different. Evidence exists about tobacco smoke's ability to elicit epigenetic changes that cause direct or indirect oxidative stress. A putative mechanism for an interaction between epigenetic modulation and environment, as identified in asthma studies, might result in increased risk for children exposed to maternal smoke [10]. Moreover, there is evidence that in utero smoke exposure may have a larger role in lung function impairment than postnatal exposure. The direct effects of maternal smoking on lung development are mainly due to the smoke components that are transferred across the placenta. Nicotine is able to cross the human placenta with minimal transformation into its metabolite "cotinine" and accumulates in amniotic fluid, several fetal tissues (including the lungs) and in maternal milk. Therefore, the fetus is exposed to even higher levels than those of the smoking mother [11].

It is well known that maternal tobacco smoking during pregnancy causes increased risk of wheezing, asthma and reduced lung function in offspring, independently from smoke exposure during postnatal life. Several studies have also demonstrated that maternal smoking during pregnancy may alter lung development in offspring. In some animal models, it has been shown that in utero smoke exposure contributes to alveolar remodeling increasing collagen deposition around large airways and vessels in offspring [12]. Furthermore, in children who died of sudden infant death syndrome (SIDS), at autopsy the inner airway wall was found thicker in those from smoking 
Table 3. Thirdhand smoke exposure and health hazards in children

\begin{tabular}{|c|c|c|c|}
\hline Author & Route of exposure & Outcome & Comment \\
\hline Elliot J, et al [13] & $\begin{array}{l}\text { Pre-natal exposure } \\
\text { in utero }\end{array}$ & $\begin{array}{l}\text { Increased inner airway wall } \\
\text { thickness at autopsy in children } \\
\text { died of SIDS (a) from smoking } \\
\text { mothers } v s \text { in those from } \\
\text { non-smoking mothers }\end{array}$ & $\begin{array}{l}\text { Airway remodeling due to in utero } \\
\text { smoke exposure may cause impaired } \\
\text { lung function in children }\end{array}$ \\
\hline Kabir Z, et al [15] & $\begin{array}{l}\text { Post-natal exposure } \\
\text { in cabin car }\end{array}$ & $\begin{array}{l}\text { Increased risk of suffering } \\
\text { from both wheeze and bronchitis } \\
\text { symptoms in exposed females }\end{array}$ & $\begin{array}{l}\text { Smoking in a car can be } 23 \text { times } \\
\text { more toxic due to the limited space }\end{array}$ \\
\hline Jung JW, et al [16] & $\begin{array}{l}\text { Post-natal exposure } \\
\text { in home }\end{array}$ & $\begin{array}{l}\text { Increased cough morbidity } \\
\text { in exposed children }\end{array}$ & $\begin{array}{l}\text { THS exposure at home can affect } \\
\text { children's lower respiratory system }\end{array}$ \\
\hline Matt GE, et al [17] & $\begin{array}{l}\text { Post-natal exposure } \\
\text { in home }\end{array}$ & $\begin{array}{l}\text { Increased cotinine levels } \\
\text { in infants from households } \\
\text { of smokers smoking outdoors } \\
\text { vs in those from households } \\
\text { of non-smokers }\end{array}$ & $\begin{array}{l}\text { Smoking outside the home and away } \\
\text { from the infant does not completely } \\
\text { protect a smoker's infant from ETS } \\
\text { exposure }\end{array}$ \\
\hline Thomas JL, et al [18] & $\begin{array}{l}\text { Post-natal exposure } \\
\text { in home }\end{array}$ & $\begin{array}{l}\text { Iso-NNAL not found in children's } \\
\text { urine sample, probably because } \\
\text { it is less readily formed from NNA }\end{array}$ & $\begin{array}{l}\text { No biomarker yet available } \\
\text { to evaluate THS exposure in humans }\end{array}$ \\
\hline
\end{tabular}

(a): Sudden Infant Death Syndrome.

versus non-smoking mothers [13]. This cumulative evidence is suggestive for airway remodeling due to in utero smoke exposure that may cause impaired lung function in children. The decreased alveolar surface area may compromise the gas-exchange capacity of the lungs, reducing tissues oxygenation. The persistent reduction in vessel density, as a result of smoke exposure during lung development, may have long term effects, such as a reduced exercise capacity and a poor tolerance to respiratory infections [12].

In addition, Blacquière recently demonstrated that smoking during pregnancy in mice is associated with increased globet cell hyperplasia and larger number of House Dust Mite-induced neutrophils and mast cells. These different aspects of remodeling may significantly contribute to the increased airway hyper-responsiveness to the allergic stimulus observed in adult mice [14].

Moreover, using a biological model of lung development, Rehan found that in utero smoke exposure alters the specific communications between epithelium and interstitium, provoking the transdifferentiation of lung lipofibroblasts to myofibroblasts, i.e. the cellular hallmark of chronic lung diseases, including asthma. Since alveolar type II cells hyperplasia and abnormal differentiation have been reported in animal models of in utero smoke exposure, it is plausible that these two findings might explain the long-term pulmonary effects (including the increased predisposition to asthma) in in utero smoke exposed children [11].

More recently, Rehan and co-workers demonstrated, in a fetal murine model, that NNK and NNA exposure resulted in breakdown of alveolar epithelial-mesenchymal cross-talk, reflecting lipofibroblast-to-myofibroblast trans-differentia- tion. This finding suggests that THS constituents may contribute to the in utero smoke exposure-induced pulmonary damage, even if further researches are necessary to define what are the risks of THS on the developing lung, considering the realistic exposure of the fetus and growing child [9].

Homes and cars today represent the main indoor environments where children are exposed to passive smoking. It has been shown that smoking exposure in a car can be 23 times more toxic than in a house due to the limited space. Moreover, smoking in a car may indirectly reflect the heavy smoking habits at home. In a survey recently conducted in Ireland one in seven schoolchildren was exposed to smoke inside cars. In particular, the study demonstrated that females are significantly more exposed and have an increased risk of suffering from both wheeze and bronchitis symptoms, compared to males of similar age [15].

A recent study conducted by Jung and coworkers demonstrated that THS exposure at home can affect children's lower respiratory system increasing cough morbidity. The Authors also noted a linear trend in the symptoms frequency among three groups according to the degree of ETS exposure (non-smoking, SHS and THS group). In fact some symptoms, including cough and nasal symptoms, were highest in the SHS group, followed by the THS and the non-smoking groups. Therefore, even if less than SHS, THS has substantial effects on children's respiratory system [16].

It has been previously demonstrated that urine cotinine levels of children living in homes with strict smoking bans are significantly lower than in homes without such policies [9]. Matt and coworkers found that ETS exposure (measured by cotinine levels in infant urine) were 5-7 times higher 
Table 4. A road-map for a smoke-free environment

\begin{tabular}{|c|c|c|}
\hline Actions & Targeted Methodologies & Endpoints \\
\hline $\begin{array}{l}\text { Educating adults and children } \\
\text { about the detrimental effects } \\
\text { of tobacco use on health }\end{array}$ & Interventions on parents and children & $\begin{array}{l}\text { Increasing public awareness about } \\
\text { THS exposure health hazards }\end{array}$ \\
\hline $\begin{array}{l}\text { Encouraging parental support } \\
\text { of school-based tobacco-prevention } \\
\text { programs }\end{array}$ & Interventions on parents & $\begin{array}{l}\text { Leading to better policies about } \\
\text { tobacco use }\end{array}$ \\
\hline $\begin{array}{l}\text { Involving general practitioners } \\
\text { and pediatricians in tobacco } \\
\text { prevention educational campaigns }\end{array}$ & Interventions on clinicians & $\begin{array}{l}\text { Including the assessment of passive } \\
\text { smoking exposure within routine } \\
\text { clinical practice }\end{array}$ \\
\hline Motivating smokers to quit & Interventions on smokers & $\begin{array}{l}\text { Creating smoke-free environment } \\
\text { for children }\end{array}$ \\
\hline
\end{tabular}

in households of smokers trying to protect their infants by smoking outdoors than in households of non-smokers. ETS exposure were 3-8 times higher in households of smokers who exposed their infants to ETS by smoking indoors than in households of smokers trying to protect their children by smoking outdoors. This suggests that smoking outside the home and away from the infant reduces but does not completely protect a smoker's infant from ETS exposure [17]. In a recent study by Thomas and coworkers, it has been attempted to detect iso-NNAL (1- (methylnitrosamino)-1-(3pyridyl)butan-4-ol, a metabolite of NNA) in the urine of children living in homes with smokers. Iso-NNAL was not detected in any urine sample, probably because this metabolite appears to be less readily formed from NNA so that the low extent of formation could have limited the ability to detect it in urine [18]. However, since currently very little is known about actual health risks attributable to THS, it is important to underscore the necessity to develop biomarkers of its exposure, especially for children.

\section{Conclusion}

Many studies clearly demonstrated that active and SHS smoking do have serious effects on children's health. Instead, there is a lack of studies of THS exposure, either in adults or in children. With the limited evidence available to date it is impossible to assess the exact role of THS in determining health outcomes in exposed people.

Hence, further investigations are warranted to study the health effects of THS relevant to different exposure pathways (inhalation, dermal contact, dust ingestion) and exposure profiles (short and long term). It would also be very important to evaluate how THS may affect the lung development through the in utero exposure during the prenatal life. In this context, it could be really interesting to validate biomarkers of exposure and tissue damage caused by THS, especially for use in children [5].

Surprisingly, there is no awareness on how can THS be a serious danger for human health. A sur- vey conducted by Winickoff et al demonstrated that only $65.2 \%$ of non-smokers and $43.2 \%$ of smokers believe that THS is harmful to children [3]. Moreover, a survey of pediatricians showed that only $13 \%$ always asked about passive smoking exposure at visits for ear infections and 33\% always gave advice to create a smoke-free home [19].

Protection of children from the detrimental effects of passive smoking has to become a high public health priority. In a recent study by Pellegrini et $a l$ it has been demonstrated a significant trend toward reduced exposure to ETS in adolescents, due to the implementation of smoke-free legislation and information campaign against smoking [20]. Educating adults about health hazards related to children THS exposure may be useful to increase public awareness of the problem and ensure a smoke-free environment for children [3].

In this context, further studies are warranted to investigate the effectiveness of the different policies aimed to protect children from exposure to passive smoking. Furthermore, in order to understand which interventions (campaigns, programs, routine clinical practice) could improve the strategies for tobacco control and promote health education a road map planning could be strongly advised (table 4).

\section{References}

1. Leonardi-Bee J, Jere ML, Britton J. Exposure to parental and sibling smoking and the risk of smoking uptake in childhood and adolescence: a systematic review and meta-analysis. Thorax 2011; 66: 847-55.

2. La Grutta S. L'impatto dell'esposizione al fumo di tabacco sulla salute respiratoria in età pediatrica. Tabaccologia 2008; 4: 36-42.

3. Winickoff JP, Friebely J, Tanski SE, et al. Beliefs about the health effects of "thirdhand" smoke and home smoking bans. Pediatrics 2009; 123: e74-9.

4. Matt GE, Quintana PJ, Zakarian JM, et al. When smokers move out and non-smokers move in: residential thirdhand smoke pollution and exposure. Tob Control 2011; 20: e1.

5. Matt GE, Quintana PJ, Destaillats H, et al. Thirdhand tobacco smoke: emerging evidence and arguments for a multidisciplinary research agenda. Environ Health Perspect 2011; 119: 1218-26. 
6. Sleiman M, Gundel LA, Pankow JF, et al. Formation of carcinogens indoors by surface-mediated reactions of nicotine with nitrous acid, leading to potential thirdhand smoke hazards. Proc Natl Acad Sci USA 2010; 107: 6576-81.

7. Burton A. Does the smoke ever really clear? Thirdhand smoke exposure raises new concerns. Environ Health Perspect 2011; 119: A70-4.

8. Schick S. Thirdhand smoke: here to stay. Tob Control 2011; 20: 1-3.

9. Rehan VK, Sakurai R, Torday JS. Thirdhand smoke: a new dimension to the effects of cigarette smoke on the developing lung. Am J Physiol Lung Cell Mol Physiol 2011; 301: L1-8.

10. Breton CV, Byun HM, Wenten M, et al. Prenatal tobacco smoke exposure affects global and gene-specific DNA methylation. Am J Respir Crit Care Med 2009; 180: 462-7.

11. Rehan VK, Asotra K, Torday JS. The effects of smoking on the developing lung: insights from a biologic model for lung development, homeostasis, and repair. Lung 2009; 187: 281-9.

12. Harding R, Maritz G. Maternal and fetal origins of lung disease in adulthood. Semin Fetal Neonatal Med 2012; 17: 67-72.

13. Elliot J, Vullermin P, Robinson P. Maternal cigarette smoking is associated with increased inner airway wall thickness in children who die from sudden infant death syndrome. Am J Respir Crit Care Med 1998; 158: 802-6.

14. Blacquière MJ, Timens W, Melgert BN, et al. Maternal smoking during pregnancy induces airway remodelling in mice offspring. Eur Respir J 2009; 33: 1133-40.

15. Kabir Z, Manning PJ, Holohan J, et al. Second-hand smoke exposure in cars and respiratory health effects in children. Eur Respir J 2009; 34: 629-33.

16. Jung JW, Ju YS, Kang HR. Association between parental smoking behavior and children's respiratory morbidity: 5-year study in a urban city of South Korea. Pediatr Pulmonol 2012; 47: 338-45.

17. Matt GE, Quintana PJ, Hovell MF, et al. Households contaminated by environmental tobacco smoke: sources of infant exposures. Tob Control 2004; 13: 29-37.

18. Thomas JL, Guo H, Carmella SG, et al. Metabolites of a tobacco-specific lung carcinogen in children exposed to secondhand or thirdhand tobacco smoke in their homes. Cancer Epidemiol Biomarkers Prev 2011; 20: 1213-21.

19. Hawkins SS, Berkman L. Increased tobacco exposure in older children and its effect on asthma and ear infections. J Adolesc Health 2011; 48: 647-50.

20. Pellegrini M, Rotolo MC, La Grutta S, et al. Assessment of exposure to environmental tobacco smoke in young adolescents following implementation of smokefree policy in Italy. Forensic Sci Int 2010; 196: 97-100.

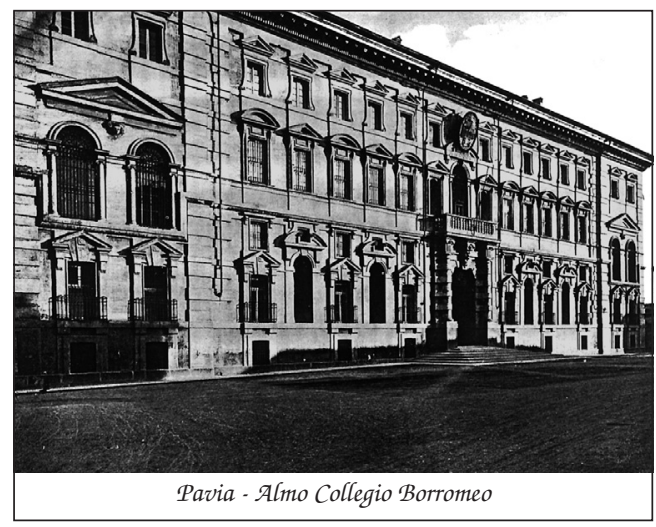

